\title{
Women with cardiovascular risk after preeclampsia: is there follow-up within the Unified Health System in Brazil?
}

\author{
Maria de Lourdes Costa da Silva ${ }^{1}$ \\ Ana Cristina Araújo de Andrade Galvão² \\ Nilba Lima de Souza ${ }^{3}$ \\ George Dantas de Azevedo ${ }^{4}$ \\ Selma Maria Bezerra Jerônimo ${ }^{5}$ \\ Ana Cristina Pinheiro Fernandes de Araújo ${ }^{4}$
}

\begin{abstract}
Objectives: to identify women with cardiovascular risk, five years after a preeclampsic episode $(P E)$, and identify the follow-up of these women within the Unified Health System (Sistema Único de Saúde - SUS), in the city of Natal/RN. Methods: a quantitative and exploratory study conducted at the Januário Cicco University Maternity Ward/RN. The sample consisted of 130 women, 65 with a PE episode and 65 who were normotensive. Results: we found statistical significance with regard to body mass index, weight, family history of cardiovascular disease (CVD) and cardiovascular complications when comparing women with previous PE to normotensive women. The groups were unaware of their cardiovascular risk factors and, in addition, they reported difficulties in accessing primary health care $(\mathrm{PHC})$ services. Conclusions: women with a PE history are at increased risk of developing CVD, unaware of late PE complications, and lacked customized care when compared to normotensive patients.
\end{abstract}

Descriptors: Lost to Follow-Up; Pre-Eclampsia; Risk Management; Cardiovascular Diseases.

\footnotetext{
${ }^{1}$ Doctoral student and Assistant Professor, Departamento de Enfermagem, Centro de Ciências da Saúde, Universidade Federal do Rio Grande do Norte, Natal, RN, Brazil.

${ }^{2}$ Doctoral student, Departamento de Enfermagem, Centro de Ciências da Saúde, Universidade Federal do Rio Grande do Norte, Natal, RN, Brazil. Professor, Escola de Enfermagem, Universidade Federal do Rio Grande do Norte, Natal, RN, Brazil.

${ }^{3}$ PhD, Professor, Departamento de Enfermagem, Centro de Ciências da Saúde, Universidade Federal do Rio Grande do Norte, Natal, RN, Brazil.

${ }^{4} \mathrm{PhD}$, Associate Professor, Centro de Biociências, Universidade Federal do Rio Grande do Norte, Natal, RN, Brazil.

${ }^{5}$ PhD, Full Professor, Centro de Biociências, Universidade Federal do Rio Grande do Norte, Natal, RN, Brazil.
}

Corresponding Author:

Maria de Lourdes Costa da Silva

Universidade Federal do Rio Grande do Norte. Centro de Ciências da Saúde

Departamento de Enfermagem

Av. Senador Salgado Filho, $\mathrm{s} / \mathrm{n}$

Campus Universitário

CEP: 59078-970, Natal, RN, Brasil

E-mail: lurdinhafoc@hotmail.com
Copyright () 2014 Revista Latino-Americana de Enfermagem This is an Open Access article distributed under the terms of the Creative Commons Attribution Non-Commercial License (CC BY-NC).

This license lets others distribute, remix, tweak, and build upon your work non-commercially, and although their new works must also acknowledge you and be non-commercial, they don't have to license their derivative works on the same terms. 


\section{Introduction}

Cardiovascular diseases (CVD) are a focus of attention for public health policies in Brazil, as they represent the leading cause of death in both sexes in our country(1). Strategies of health education, professional training and preventive measures have been implemented since the increase in these events among women aged less than 55 years. Nevertheless, measures to reduce cardiovascular damage need to move forward, as the cause of the disease remains unknown, while several risk factors may contribute to its occurrence.

In women, the following aggravating factors for CVD could be highlighted: gestational hypertension, preeclampsia (PE) and eclampsia, diabetes mellitus, and obesity $^{(2)}$. In this sense, the American Heart Association guidelines consider PE to be a major complication of pregnancy associated with cardiovascular risk(3).

Preeclampsia is a systemic disorder identified by the presence of hypertension and proteinuria after 20 weeks of pregnancy ${ }^{(4)}$, with an incidence of approximately $10 \%$ of pregnancies ${ }^{(5)}$. It is considered to be an extremely serious complication for the pregnancy-childbirth cycle, by corroborating with the occurrence of metabolic after-effects in the shortand long-term, causing an increased cardiovascular risk. Based on these outcomes, PE is identified as an independent and relevant risk factor for $\mathrm{CVD}^{(6)}$.

Thus, one may recommend the promotion of clinical and subclinical assessments during the postpartum period, with measures of health education and stimulus for lifestyle changes among women affected by $\mathrm{PE}^{(7)}$. Likewise, a systematic follow-up is required, as well as the identification and monitoring of cardiovascular risk factors by health professionals involved in primary health care (PHC), in order to reduce morbidity and mortality of CVD in this population ${ }^{(3)}$.

For the accomplishment of this comprehensive care, PHC services should be easily accessible and available to the population. Otherwise, the demand for care may be delayed, affecting the diagnosis and the implementation of the necessary actions to address this health problem. Thus, accessibility is one of the most important characteristics of $\mathrm{PHC}$, directly related to its effectiveness, transcending the geographical dimension and including economic, cultural and organizational aspects of care delivery ${ }^{(8)}$.

It is noteworthy to note that after the Family Health Strategy (FHS) implementation, an increase in access and equity offered to the population was observed(8).
However, health services still do not seem prepared to recognize women with a history of $\mathrm{PE}$ as being vulnerable to CVD. These users are embedded in a care context that places them on the same level as any other woman from the general population. Usually, care is fragmented, punctual, and occurs through self-referral, which does not always reflect the needs of the population. Despite this fact, it is necessary for the Unified Health System and health professionals to possess the required competencies to conduct reasonable interventions, thus promoting improved quality of life and minimizing diseases and disorders based on risk factors ${ }^{(9)}$.

Bearing in mind the associations of PE with the long-term occurrence of CVD and the findings on the importance of early diagnosis and identification of risk factors of these diseases in the pre-partum period, the presented facts impose the need of conducting prospective studies to better comprehend the follow-up of this population in $\mathrm{PHC}$ settings ${ }^{(10)}$.

In this sense, this study is relevant from an epidemiological perspective, and its findings may provide information to managers and health professionals on the real condition of the cardiovascular risk of women who had $\mathrm{PE}$, in order to drive effectiveness of health policies for systematic follow-up during the late postpartum period.

Faced with this problem, we raised the following question: What are the cardiovascular risk factors in women with a history of PE five years ago? Are these women being followed up in PHC services?

Given these questions, the study aimed to identify women with cardiovascular risk factors, five years after a preeclampsic event (PE), and assess the follow-up in $\mathrm{PHC}$ services of these women.

\section{Methods}

An exploratory and descriptive study with a quantitative approach was conducted in the University Maternity Ward - MEJC, a tertiary-level institution for health care for women with high-risk pregnancies, located in the city of Natal/RN.

The study population consisted of 311 women selected from the database of the women's health research group of the Federal University of Rio Grande do Norte. Patients with a previous history of PE, and normotensive women who had their deliveries at this maternity ward, five years prior to the initiation of the research, were included in the study.

The inclusion criteria were considered to be the following: presenting with a clinical and laboratory 
diagnosis of $\mathrm{PE}$, without any mental deficit, a resident of the city of Natal, RN. For sample size calculation, we considered a limit of $5 \%$ on the estimation error for the sample proportion, and a $50 \%$ population proportion of women with PE history, leading us to a conservative sample size estimation, i.e., obtaining a sample possibly greater than what was necessary. The sample size estimated a total number of 175 women, 87 of these with previous PE and 88 who did not develop any form of hypertension in pregnancy. The study subjects were selected by simple random sampling.

We adopted as exclusion criteria: previous personal history of CVD, cognitive or neurological sequelae, and inadequate completion of information regarding the diagnosis of PE in the medical records. A total of 22 women did not participate in the study, 14 for lack of diagnostic confirmation of PE in the database records, and eight refused to take part in research. Regarding the group of normotensive women, 13 did not fit the inclusion criteria and ten did not volunteer for the study. The final representative sample for this population consisted of 130 women eligible for the study, classified into two groups according to the diagnosis status: normotensive $(n=65)$ and PE $(n=65)$.

The survey was conducted from March to December of 2011. Initially, we contact the study subjects directly in their homes, and proceeded giving detailed explanations about the characteristics and purposes of the study, indicating the venue and date of data collection, commonly in the PHC facilities closest to their homes in the city of Natal.

For data collection, a questionnaire was administered. This was composed of items related to qualitative variables such as marital status, income, education, occupation, types of delivery, family history of CVD, current cardiovascular complications, knowledge of cardiovascular risk factors, frequency of health services utilization, blood pressure measurement, health staff follow-up, health service of reference, and access to medical visits. Quantitative variables were age, weight, body mass index (BMI), and number of deliveries.

The instrument was based on documents of experts in high-risk pregnancy studies and on publications about the promotion of long-term care in women with cardiovascular risk $^{(3-4)}$. We guaranteed the credibility of collected data through the validation of instrument content and form, which was conducted in two stages: first the content was judged by a group of five experts in obstetrics and in high risk pregnancies, who evaluated the questionnaire items as comprehensive, representative and easy to understand for the study subject. Later, we conducted instrument pre-testing with 13 women who were not part of the survey, representing $10 \%$ of the selected sample. There was no identified need for modifications to suit the purpose of the investigation.

After completing the questionnaire, we held anthropometric measurements (weight and height) among the study participants, as recommended by the World Health Organization (WHO). To assess the nutritional status (overweight and obesity), women were classified according to the BMI obtained, using the WHO recommended cutoffs: underweight for BMI $<18.4 \mathrm{~kg} / \mathrm{m}^{2}$, appropriate weight for BMI ranging from 18.5 to $24.9 \mathrm{~kg} / \mathrm{m}^{2}$, overweight for BMI of 25.0 to $29.9 \mathrm{~kg} / \mathrm{m}^{2}$, and obesity for values above $30.0 \mathrm{~kg} / \mathrm{m}^{2(11)}$.

The project was approved by the Federal University of Rio Grande do Norte Board of Ethics, process number CEP-UFRN 08/01, and all participants received information about the importance of the research, the voluntary nature of the project, and free consent was guaranteed in accordance with the National Health Council Resolution 196/96(12)

For data analysis we used the Statistical Package for the Social Sciences - SPSS, version 17.0. To verify the association between qualitative variables and the diagnosis of PE or the normotensive status, we used the chi-square test. To correlate the level of education with the level of knowledge, we applied the Spearman correlation test. The BMI variables and the number of pregnancies did not follow the normality assumptions, and therefore the Mann-Whitney test for comparison of means was used, while in the other quantitative variables we applied the Student t-test, since these variables passed the normality test. For all tests, we used a $5 \%$ level of significance.

\section{Results}

The two studied groups of women shared similar social and demographic characteristics. The mean age ranged from 30.85 years (SD \pm 7.13 ) and 30.58 years $(\mathrm{SD} \pm 6.75)$, respectively (Table 1$)$, the unmarried union was the predominant marital status (63.07\%) and high school was the educational level of the majority of women (59.23\%). The family income was up to three minimum wages in $94.61 \%$ of patients and $62.30 \%$ reported household activities as the current occupation.

In regard to obstetric characteristics, we found a statistical significance between groups. C-section 
was predominant among women diagnosed with PE ( $85.94 \%)$, compared to $31.75 \%$ among normotensive group $(p=0.000)$. The number of pregnancies between groups was similar $(p=0.184)$.

Anthropometric data, presented in Table 1, revealed a high rate of increased BMI among the PE group, averaging $30.68 \mathrm{~kg} / \mathrm{m}^{2}$ (SD \pm 10.85 ), a classification compatible with obesity. The normotensive group mean value for BMI was $26.69 \mathrm{~kg} / \mathrm{m}^{2}$ (SD \pm 6.50 ), indicating overweight. There was a statistically significant difference between the two groups, respectively: $p=0.001$ and $p=0.008$.

Table 1 - Distribution of mean values and standard deviation related to age, weight and BMI in normotensive women group and history of preeclampsia group. Natal, RN, Brazil, 2011

\begin{tabular}{|c|c|c|c|c|c|c|}
\hline \multirow{2}{*}{ Variables } & \multicolumn{2}{|c|}{ Normotensive } & \multicolumn{2}{|c|}{ Preeclampsia } & \multirow{2}{*}{ Test } & \multirow{2}{*}{$p$-value } \\
\hline & Mean & SD* $^{*}$ & Mean & SD & & \\
\hline Age & 30.58 & 6.754 & 30.85 & 7.133 & -0.215 & $0.830^{+}$ \\
\hline Weight & 64.00 & 15.652 & 71.40 & 15.732 & -2.688 & $0.008^{\dagger}$ \\
\hline Body Mass Index & 26.69 & 6.504 & 30.68 & 10.852 & $1,412.50$ & $0.001^{\ddagger}$ \\
\hline
\end{tabular}

*Standard deviation

+Student-T test

‡Mann-Whitney test

Clinical characteristics and cardiovascular risk factors are shown in Table 2. The findings indicate that in terms of the family history for CVD - including hypertension, myocardial infarction, angina and cerebral vascular attack $-93.85 \%$ of women affected by PE and
$76.92 \%$ of those normotensive reported the existence of CVD in a first-degree relative. There was a significant difference between the study participants $(p=0.006)$ concerning this data.

Table 2 - Clinical characteristics and cardiovascular risk factors in normotensive women group and history of preeclampsia group. Natal, RN, Brazil, 2011

\begin{tabular}{|c|c|c|c|c|c|}
\hline \multirow{2}{*}{ Variables } & \multicolumn{2}{|c|}{ Normotensive } & \multicolumn{2}{|c|}{ Preeclampsia } & \multirow[t]{2}{*}{$p$-value* } \\
\hline & $\mathbf{n}$ & $\%$ & $\mathbf{n}$ & $\%$ & \\
\hline Current cardiovascular complications & & & & & 0.002 \\
\hline No & 61 & 93.85 & 48 & 73.85 & \\
\hline Yes & 4 & 6.15 & 17 & 26.15 & \\
\hline Familiar history of cardiovascular diseases & & & & & 0.006 \\
\hline No & 15 & 23.08 & 4 & 6.15 & \\
\hline Yes & 50 & 76.92 & 61 & 93.85 & \\
\hline Blood pressure monitoring & & & & & 0.108 \\
\hline No & 57 & 87.69 & 50 & 76.92 & \\
\hline Yes & 8 & 12.31 & 15 & 23.08 & \\
\hline Cardiovascular risk knowledge & & & & & 0.861 \\
\hline No & 33 & 50.77 & 34 & 52.31 & \\
\hline Yes & 32 & 49.23 & 31 & 47.69 & \\
\hline
\end{tabular}

Regarding unexpected events and complications in current health status, $26.15 \%$ of women with a history of PE reported some cardiovascular occurrence, such as hypertension episodes. This event occurred in only $6.15 \%$ of normotensive women, evidencing a statistical significance between groups $(p=0.002)$. Regarding frequency of blood pressure monitoring, $76.92 \%$ of $\mathrm{PE}$ respondents reported that health professionals did not manage blood pressure control, similar to the $87.69 \%$ reported by the normotensive women $(p=0.108)$. Regarding participants' knowledge about CVD risk factors, the findings pointed out deficiencies both in the PE group (52.31\%), as well as in the normotensive group $(50.77 \%)(p=0.861)$. Table 3 shows a significant positive correlation between the level of education and knowledge of cardiovascular risk factors in the PE group $(r=0.250, p=0.044)$ and normotensive group $(r=0.318$, $p=0.010)$. 
Table 3 - Correlation between education level and knowledge of risk factors of cardiovascular and normotensive women with a history of preeclampsia. Natal, RN, Brazil, 2011

\begin{tabular}{|c|c|c|c|c|c|c|c|}
\hline \multirow{3}{*}{ Diagnosis } & \multirow{3}{*}{ Education } & \multicolumn{4}{|c|}{ Knowledge of CVD risk factors } & \multirow{3}{*}{$\mathbf{r}^{*}$} & \multirow{3}{*}{$\mathbf{p}^{\dagger}$} \\
\hline & & \multicolumn{2}{|c|}{ No } & \multicolumn{2}{|c|}{ Yes } & & \\
\hline & & $\mathbf{n}$ & $\%$ & $\mathbf{n}$ & $\%$ & & \\
\hline \multirow[t]{4}{*}{ Normotensive } & No schooling & 1 & 3.0 & 0 & 0.0 & 0.318 & 0.010 \\
\hline & Primary education & 19 & 57.6 & 9 & 28.1 & & \\
\hline & High school & 12 & 36.4 & 22 & 68.8 & & \\
\hline & University education & 1 & 3.0 & 1 & 3.1 & & \\
\hline \multirow[t]{4}{*}{ Preeclampsia } & No schooling & 1 & 2.9 & 0 & 0.0 & 0.250 & 0.044 \\
\hline & Primary education & 16 & 47.1 & 7 & 22.6 & & \\
\hline & High school & 15 & 44.1 & 23 & 74.2 & & \\
\hline & University education & 2 & 5.9 & 1 & 3.2 & & \\
\hline
\end{tabular}

*Correlation coefficient

+Probabilities of the Spearman correlation test

Table 4 shows that $89.09 \%$ of PE participants and $90.00 \%$ of normotensive women had no follow up by any health professional $(p=0.639)$. With regard to accessibility, the majority of respondents both in the normotensive group (93.85\%) and PE group $(92.31 \%)$ reported attending their health service of reference $(p=0.730)$. However, $72.31 \%$ and $67.69 \%$ of participants with normal blood pressure and previous
$\mathrm{PE}$, respectively, reported having difficulties in accessing PHC services $(p=0.548)$; additionally, independent of experiencing a normal pregnancy (86.15\%) or developing PE (75.38\%), they rarely sought medical care due to difficulties such as: insufficient number of medical practitioners, inconvenient appointment hours, inefficient referrals, and unavailability of medications $(p=0.119)$.

Table 4 - Distribution of the population according to PHC services follow-up, Natal, RN, Brazil, 2011

\begin{tabular}{|c|c|c|c|c|c|}
\hline \multirow{2}{*}{ Variables } & \multicolumn{2}{|c|}{ Normotensive } & \multicolumn{2}{|c|}{ Preeclampsia } & \multirow{2}{*}{$p$-value } \\
\hline & n & $\%$ & $\mathbf{n}$ & $\%$ & \\
\hline Follow-up by a health professional & & & & & $0.639 *$ \\
\hline No & 18 & 90.00 & 49 & 89.09 & \\
\hline Yes & 2 & 10.00 & 6 & 10.91 & \\
\hline Health service of reference & & & & & $0.730^{*}$ \\
\hline No & 4 & 6.15 & 5 & 7.69 & \\
\hline Yes & 61 & 93.85 & 60 & 92.31 & \\
\hline Accessibility & & & & & $0.548^{*}$ \\
\hline Difficult & 47 & 72.31 & 44 & 67.69 & \\
\hline Easy & 18 & 27.69 & 20 & 30.77 & \\
\hline Private & 0 & 0.00 & 1 & 1.54 & \\
\hline Medical visit & & & & & 0.119 \\
\hline Rarely & 56 & 86.15 & 49 & 75.38 & \\
\hline Regular & 9 & 13.85 & 16 & 24.62 & \\
\hline
\end{tabular}

\section{Discussion}

This research, which aimed to assess the followup of women with a history of PE, corroborated other studies that showed the close relationship of this disease with metabolic alterations and cardiovascular risk from a long-term perspective ${ }^{(13)}$. The BMI among the PE group was significantly higher than in women with a history of normal pregnancy. These data were consistent with similar studies that also found increased BMI in women with previous $\mathrm{PE}^{(5,14)}$.
A higher rate of cesarean delivery among women with previous PE when compared with women who had normal pregnancies was consistent with results from a previous study that showed a higher percentage of cesarean delivery in women affected by hypertension in pregnancy(15). However, the American College of Obstetrics and Gynecology recommends vaginal delivery for woman with $\mathrm{PE}$, due to maternal benefits, greater likelihood of success with induction, and a decreased risk of bleeding complications ${ }^{(4)}$. The suggestive clinical 
findings of cardiovascular events in the participants with PE differed from previous studies, which recorded the occurrence of CVD occurring about 10 years after the PE episode(6,16).

The higher prevalence of family history of CVD among women affected by PE when compared with the normotensive women suggests that cardiovascular risk factors were often related to genetic predisposition and environmental factors ${ }^{(17)}$. However, authors restated that, independent of traditional CVD risk factors, including family history, hypertensive disorders during pregnancy may increase CVD occurrence over time ${ }^{(18)}$.

Regarding the follow-up of women with PE investigated in this study, it was found that despite being a vulnerable group for the development of CVD, and being covered by the Family Health Strategy teams with the availability of a reference health unit in the neighborhood, this action was not being performed due to constraints in women's access to these services. This might be related to the disintegration of health care networks and the breach of Unifed Health System principles ${ }^{(19)}$.

International guidelines recommend a routine control and annual reassessment of blood pressure (BP) of women affected by $\mathrm{PE}^{(3)}$. However, both groups reported that they had not their BP monitored. Similar studies have shown BP monitoring frequency in women with PE lasting for a maximum period of three months after delivery, which contributed to increased cardiovascular risk ${ }^{(20)}$.

The data also showed that the previous history of PE was not relevant in determining a differentiated service when comparing the PE group to normotensive patients. This circumstance could be minimized if PHC services organization provided adequate physical infrastructure and inputs for appropriate follow-up. Furthermore, a competent interdisciplinary team committed to the development of actions in at risk populations is needed, aiming to address preventable diseases and monitoring the current health events ${ }^{(8)}$.

Another important aspect in which there was no distinction between PE and normotensive groups was the poor knowledge about cardiovascular risk factors. Although they have been informed during pregnancy about their hypertension status, women were apparently not advised about the possible consequences of the disease and the need for follow-up and lifestyle changes, such as healthy eating, physical activity, regular BP control, among others. It is also considered that the lack of knowledge corroborated to the irregular seeking of care among women with previous PE.
Thus, the interdisciplinary team should prioritize health education targeted to this specific population during pregnancy and delivery, and also at the time of hospital discharge, with a consistent approach for the socioeconomic and educational context of patients.

In this perspective, the nurse, as a key element in the care process, acts in identifying the risks of illness and preventing injuries. Therefore, one needs to review his/her clinical practice to organize care in a comprehensive manner, focusing on the uniqueness and autonomy of patients ${ }^{(21)}$.

\section{Conclusions}

The findings indicated that women with a family history of CVD, presenting obesity and current CVD suggestive of clinical manifestations were at risk for developing unexpected cardiovascular events, enhanced by their previous history of PE. However, comprehensive care and adequate follow-up in the primary health care network were not found.

Therefore, it is necessary to maintain a solid referral structure and a qualified interdisciplinary team, in which the nurse is inserted, to promote early diagnosis and adequate follow-up of women with cardiovascular risk factors through health education during the pregnancy and the puerperium, as well as at the time of hospital discharge. This would focus on the acquisition of knowledge regarding late complications of this disease and the importance of long-term outpatient treatment, emphasizing clinical data monitoring and adoption of a healthy lifestyle.

This study was limited by the difficulties in locating the study subjects due to frequent changes of address and telephone numbers, which did not allow further expansion of the sample size. It is necessary to conduct new studies to investigate the functioning and integration of health care services for women in pregnancy and puerperium, especially those with a cardiovascular risk, to design strategies for quality women's health care and outcome improvement, and also to support the findings of this study.

\section{References}

1. Mansur AP, Favarato D. mortalidade por doenças cardiovasculares no Brasil e na região metropolitana de São Paulo: atualização. 2011. Arq Bras Cardiol. 2012;99(2):755-61.

2. Valdiviezo C, Garovic VD, Ouyang P. Preeclampsia and Hypertensive Disease in Pregnancy: Their Contriibutions to Cardiovascular Risk. Clin Cardiol. 2012;35(3):160-5. 
3. Mosca L, Benjamin EJ, Berra K, Bezanson JL, Dolor RJ, LIoyd-Jones DM, et al. Effectiveness-based guidelines for the prevention of cardiovascular disease in women-2011. Update: a guideline from the American Heart Association. Circulation. 2011;123:1243-62.

4. American College of Obstetricians and Gynecologistis. Diagnosis and Management of preeclampsia and Eclampsia. Obstet Gynecol. 2002;33:159-67.

5. Mangos GJ, Spaan JJ, Pirabhahar, Brown MA. Markers of cardiovascular disease risk after hypertension in pregnancy. J. Hypertens. 2012;30(2):351-8.

6. McDonald SD, Malinowski A, Zhou Q, Yusuf $S$, Devereaux PJ. Cardiovascular sequelae of preeclampsia/ eclampsia: a systematic review and meta-analyses. Am Heart J. 2008;156(5):918-30.

7. Firoz, T, Melnik T. Postpartum evaluation and long term implications. Best Pract Res Clin Obstet Gynaecol. 2011;25(4):549-61.

8. Ministério da Saúde (BR). Conselho Nacional de Secretários de Saúde. Atenção Primária e Promoção da Saúde. Conselho Nacional de Secretário de Saúde. Brasília: Conselho Nacional de Secretário de Saúde; Ministério da Saúde; 2011.

9. Carolino IDR, Molena-Fernandes CA, Tasca RS, Marcon SS, Cuman RKN. Risk factors in patients with type 2 diabetes mellitus. Rev. Latino-Am. Enfermagem. 2008; 16(2):238-44.

10. Melo BCP, Amorim MMR, Katz L, Coutinho I, Veríssimo G. Perfil Epidemiológico e Evolução Clínica Pós-Parto na Pré-Eclampsia Grave. Rev Assoc Med Bras. 2009;55(2):175-80.

11. World Health Organization. Physical status: the use and interpretation of anthropometry. Report of a WHO Expert Committee. World Health Organ Tech Rep Ser. 1995;854:1-452.

12. Resolução 196, de 10 de outubro de 1996 (BR). Dispõe sobre as diretrizes e normas regulamentadoras de pesquisa em seres humanos. 1996. [acesso $28 \mathrm{fev}$ 2013]. Disponível em: http://www.ee.usp.br/pesq/doc/ resolucao_196-96.pdf

13. Forest JC, Girouard J, Massé J. Early ocurrence of metabolic syndrome after hypertension in pregnancy. Obstet Gynecol. 2005;105:1373-80.

14. Lu J, Zhao YY, Qiao J, Zhang HJ, Ge L, Wei Y, et al. A follow-up study of women with a history of severe preeclampsia: relationship between metabolic syndrome and preeclampsia. Chin Med J. 2011;124(5):775-9.

15. Pádua KS, Osis MJD, Faúndes A, Barosa AH, Moraes OB Filho. Fatores associados à realização de cesariana em hospitais brasileiros. Rev Saúde Pública. 2010;44(1):70-9.
16. Smith, GN, Pudwell J, Walker M, Wen SW. Tenyear, thirty-year, and lifetime cardiovascular disease risk estimates following a pregnancy complicated by preeclampsia. J Obstet Gynaecol Can. 2012;34(9):830-5.

17. Cesarino CB, Cipullo JP, Martins JFV, Ciorlia LA, Godoy MRP, Cordeiro JA. Prevalência e Fatores Sociodemográficos em Hipertensos de São José do Rio Preto-SP. Arq Bras Cardiol. 2008;91(1):31-5.

18. Cassidy-Bushrow AE, Bielak LF, Rule AD, Sheedy PF, Turner ST, Garovic VD, et al. Hypertension during pregnancy is associated with coronary artery calcium independent of renal function. J. Womens Health. (Larchmt). 2009;18(10):1709-16.

19. Travassos C, Martins M. Uma revisão sobre os conceitos de acesso e utilização de serviços de saúde. Cad Saúde Pública. 2004;20 Suppl:190-8.

20. Macdonald SE, Walker M, Ramshaw H, Godwin M, Chen XK, Smith G. Hypertensive disorders of pregnancy and long-term risk of hypertension: what do Ontario prenatal care providers know, and what do they communicate? J Obstet Gynaecol Can. 2007;29:705-10. 21. Nauderer TM, Lima MAD. Nurses' practices at health basic units in a city in the south of Brazil. Rev. LatinoAm. Enfermagem. 2008;16(5):889-94.
Received: Mar. 25 2013 Accepted: Sept. 23 2013 